\title{
ADRC Performance in Power Control of DFIG used in Wind Turbine During Grid Voltage Fault
}

\author{
A. Boualouch ${ }^{1 *}$, A. Essadki ${ }^{1}$, T. Nasser ${ }^{2}$, A. Frigui ${ }^{1}$ and A. Boukhriss ${ }^{1}$ \\ ${ }^{1}$ Electrical Engineering Laboratory, High school of education (ENSET), \\ Mohammed V University, Rabat, Morocco \\ ${ }^{2}$ Communication networks department of National High School for Computer \\ Science and Systems (ENSIAS), Mohammed V University, Morocco \\ *abdellah.boualouch@um5s.net.ma
}

\begin{abstract}
This paper presents the performance of Active Disturbance Rejection Control (ADRC) applied to power control of Doubly Fed Induction Generator (DFIG) used in wind turbine during the grid voltage fault such as overvoltage and under voltage.

In the situation of a grid fault, the characteristics of the grid changes and also the wind turbine might lose the connection with the grid. The main objective of this article is to evaluate the ADRC performance, and to propose an improved power control of DFIG during the voltage fault without losing the connection with the grid in case of overvoltage and undervoltage fault.

The improvement method is based on ADRC controller and adding a circuit to protect the vulnerable rotor converters such as a DC Chopper and a Serial Active Crowbar Resistance (SACR).

In this article we synthesize the ADRC controllers applied to turbine, Rotor Side Converter (RSC) and Gride Side Converter (GSC) control strategy. The dynamic model of $D F I G$ and wind system are simulated in Matlab-Simulink environment.
\end{abstract}

Keywords: ADRC, DFIG power, wind energy, overvoltage, undervoltage, voltage fault

\section{Introduction}

Most of the last research works are interested in renewable energies as they play a key role in solving problems related to electrical energy such as the exhaustion of fosil of fuel and the release of greenhouse gas (global warming) [1].

Wind power is a clean energy and environmentally friendly. This type of energy can contribute significantly to the energy development as it's free, clean and renewable;

In addition, it has great potential and so many wind farms are in service worldwide [2].

Morocco is a great example; the kingdom has priority to develop the wind power on the whole territory for which the kingdom plans to reach a capacity of 2000 MW by 2020 [3].

Studies in the development of wind energy are more interested in DFIG model rather than the electromechanical conversion [13]. The DFIG is largely used in this area for its benefits in the case of operating under variable speed and size of the rotor converters.

However, researchers in the field today are also interested in the efficiency of the electrical energy supply and wind turbines. In fact, a turbine connected to the grid can suffer from the electrical grid fault (such the sudden nominal voltage variation line to line). This type of defect is known in the field of wind energy research as the LVRT [2].

Received (January 23, 2018), Review Result (April 30, 2018), Accepted (May 10, 2018)

* Corresponding Author 
The main purpose of the studies accomplished in that field is to ensure the protection of the turbine equipments (such as the rotor converters) during grid voltage fault without tripping of the circuit breakers. The parameters of the circuit breakers will be not changed.

In this paper overvoltage and undervoltage fault are applied to DFIG (during voltage fault DC shopper is used for DC voltage limitation, and the Crowbar resistance for fault currents limitation). In literature several works are published about crowbar and DC shopper [2]-[14] (the two components are without effect in normal condition).

\section{Voltage Grid Fault}

\subsection{Power Quality}

The power quality is often defined as the electrical network's or the grid's ability to ensure a clean and stable power supply. The power quality covers three concepts:

a. Stable power supply

This aspect covers electrical blackout or interruptions. There are a number of criteria for classifying these blackout, such as scheduled and unscheduled blackout, long (more than 3 minutes) and short blackout (between 1 and 179 second). For blackout of less than 1 second, although the terms "very short black" and "cut-off" are sometimes used, it is generally referred to as voltage dips [4].

b. Voltage wave quality

This aspect covers the disturbances related to the voltage waveform delivered by the grid, which can alter the functioning of the electrical machines connected to the grid, or even damage them. Different terms can be used depending on the characteristics of the disturbance: voltage dips, phase imbalance, pulse over voltages, flicker, high or low voltages, frequency variations, harmonic and inter-harmonic rates, etc. the following figure presents the voltage waves disturbances.

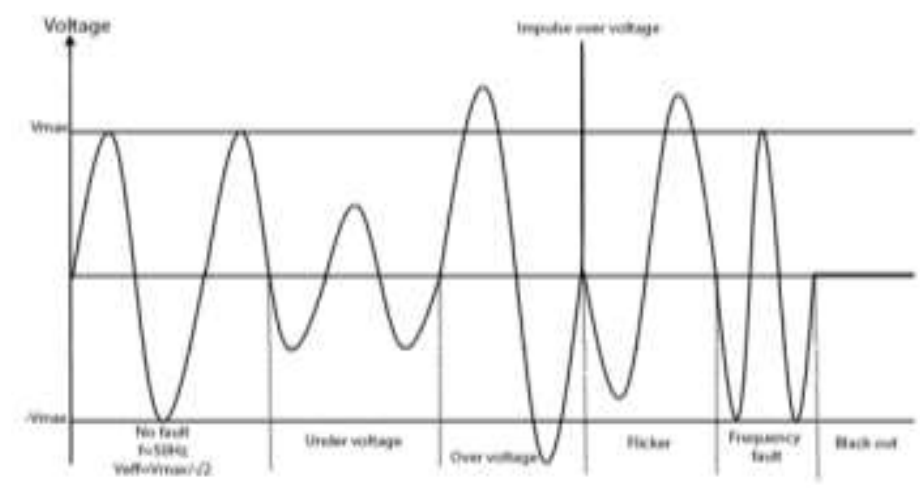

Figure 1. Voltage Waves Disturbances

\section{c. Electrical service Quality}

This parameter characterizes the relation between a user and the network operator (emergency response time, commissioning time, connection delay, scheduled shutdown notification, etc.,).

\subsection{Voltage Wave Quality}

The AC power grids are voltage wave delivered by the electrical system ideally takes the form of a sinusoid of frequency and amplitude. However, in reality, the voltage wave 
is never perfectly sinusoidal, the frequency and the amplitude of this wave constantly varies.

If the variation of voltage wave is more important, the functioning of some electrical machines connected to the grid such as wind turbines, production plants, domestic appliances, industrial machines, may be disturbed. In the most extreme cases, this can range from the impossibility of operating during the duration of the disturbance [5], to longterm material damage or, more rarely, to instantaneous material damage. To sum-up we can distinguish the following grids default type, each disturbance has a specific effect on the network or on the electrical device:

- Voltage dips

- Impulse overvoltage

- Flicker

- Undervoltage

- Overvoltage

- Frequency fluctuation

- Imbalance

- Harmonics and inter-harmonics

\subsection{Wind turbine and Voltage Grid Fault}

Wind turbines connected to the grid can be badly affected by voltage grid fault even the punctual and smallest ones. This can cause many technical problem and malfunctions to the equipments that need a permanent and sustainable energy supply.

The shut-down of a high-power load such as high voltage motors, high-power engines and Electrical Arc Furnas EAF can cause an increase in grid voltage. In the other hand, the high-currents in power lines or a short-circuit in the grid can cause voltage dpis with a sudden decrease of the nominal voltage value which varies between $10 \%$ and $90 \%$ during a time betwen 10 to $1000 \mathrm{~ms}$ [6].

The effects of the voltage fault on a wind turbine are multiple; one of them is the dysfunction and the disconnection of the turbine with the wind turbine system.

In the other side, the electromechanical converter (DFIG in our case) may be sensible to voltage fault, especially if we know that during a voltage fault even if relatively low, stator current increases because of the direct coupling betwen the grid and the stator of the machine.

The fault current will pass through the rotor and the power converter causing a rotor over-current and an increase in the DC bus voltage [6].

In order to protect the rotor converter against the effect of the voltage fault, it's necessary to use the active circuit voltage limiting such as Crowbar resistance and DC Shopper.

\section{Active Disturbance Rejection Control}

The parameters of the majority of physicals systems are subject to frequent variation, consequently, the conventional controllers are less efficient and less robust. Today, modern controllers are based on the estimation of perturbations through observers.

It is within this context that the ADRC proposes real-time estimation and cancellation of various internal or external perturbations using an Extended State Observer (ESO) [1][2]- [7] - [12].

This type of observers allows to estimate the external perturbations and also the internal dynamics of the system. 


\subsection{ADRC for Linear System}

In general, for a system of $\mathrm{n}$ order, which can be written in the form:

$$
y(t)^{(t)}=f\left(y(t)^{(n-1)}, y(t)^{(n-2)}, \ldots, y(t), d(t)\right)+b u(t)
$$

Where:

f: Dynamic unknown parameter of the system

d: disturbance

b: Constant parameter

$\mathrm{u}$ : control law

For the estimation of the total disturbances, the control law adopted for this system is:

$u=\frac{-f+u_{0}}{b}$

In this case, the equation (1) can be written as follows

$y^{(n)}=\frac{\widehat{f}+u_{0}}{b} \approx u_{0}$

In a first-order system, the equation (1) becomes:

$\dot{y}=(y, d, t)+b_{0} u$

The ESO equation is written in matrix form as shown below:

$$
\dot{X}=A X+B u+E h
$$

Where:

$A=\left[\begin{array}{cccc}0 & 1 & \ldots & 0 \\ \vdots & & \ddots & \vdots \\ 0 & 0 & \ldots & 1 \\ 0 & 0 & \ldots & 0\end{array}\right]_{(n+1) \times(n+1)}, B=\left[\begin{array}{c}0 \\ \vdots \\ b \\ 0\end{array}\right]_{(n+1)}$ and $E=\left[\begin{array}{c}0 \\ \vdots \\ 0 \\ 1\end{array}\right]_{(n+1)}$

The extended state observer ESO established for equation (4) as:

$\left\{\begin{array}{l}\dot{Z}=A Z+B u+G(y-\bar{y}) \\ \hat{y}=C Z\end{array}\right.$

With:

$Z^{T}=\left[\begin{array}{llll}z_{1} & z_{2} & \ldots & z_{n+1}\end{array}\right], G^{T}=\left[\begin{array}{llll}g_{1} & g_{2} & \ldots & g_{n+1}\end{array}\right], C=\left[\begin{array}{llll}1 & 0 & \ldots & 0\end{array}\right]$

To determine the parameters of $\mathrm{G}$, we have:

$g_{n}=\omega_{0}^{n} \beta_{n}$

For a first-order system, we write the equation of the linear extended state observer ESO in the form:

$\left\{\begin{array}{l}\dot{z}=A z+b_{0} B u+G(y-\bar{y}) \\ \hat{y}=C z\end{array}\right.$

With:

$A=\left[\begin{array}{cc}0 & 1 \\ 0 & 0\end{array}\right] ; B=\left[\begin{array}{l}1 \\ 0\end{array}\right] ; C^{T}=\left[\begin{array}{l}1 \\ 0\end{array}\right] ; G=\left[\begin{array}{c}2 \omega_{0} \\ \omega_{0}^{2}\end{array}\right]$

The control law is written: 
$u=\frac{u_{0}-z_{2}}{b_{0}}$

The system described in the equation (4) is then reduced to a simple integrator easily controllable by a proportional corrector kp.

$\dot{y}=\left(f-z_{2}\right)+u_{0} \approx u_{0}$

With:

$u_{0}=k_{p}\left(Y_{\text {ref }}-z_{1}\right) \quad$ and $\quad k_{p}=\omega_{c}$

Where Yref is the entry reference to follow and $\omega_{0}$ is an observer bandwidth for ESO.

\subsection{ADRC for Non Linear System}

For the non-linear structures, the state observer equation is written as [8]:

$\left\{\begin{array}{l}\dot{z}=z_{2}-a_{1} f a l\left(e, \alpha_{1}, \delta_{1}\right) b_{0} u \\ \dot{z}_{2}=a_{2} \operatorname{fal}\left(e, \alpha_{2}, \delta_{2}\right) \\ e=z_{1}-y\end{array}\right.$

With:

fal: is a nonlinear function developed by Jingqing Han [11] such as:

$f a l(e, \alpha, \delta)= \begin{cases}|e|^{\alpha} \operatorname{sign}(e) \text { if }|e| \geq \delta \\ \frac{e}{\delta^{1-\alpha}} \quad \text { if }|e| \prec \delta\end{cases}$

The control law is given by:

$u_{0}=k_{p} f a l\left(Y_{r e f}-z_{1}, \alpha, \delta\right)$

With:

$\alpha$ is to be adjusted and which value is between 0 and 1 [10].

$\delta$ is inferior to 1 .

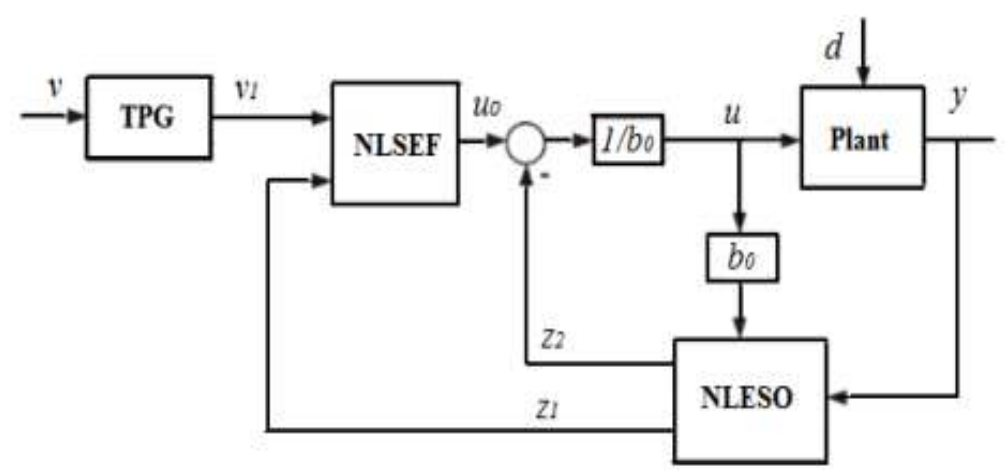

Figure 2. Architecture of ADRC Controller

\subsection{ADRC for WECS Control}

Pitch angle control: 
The pitch angle is controlled so that the Wind Energy Conversion System (WECS) operates in its safe region and to extract the maximum electrical power from the turbine. We consider the following equation:

$$
\frac{d \Omega_{m}}{d t}=\frac{1}{J}\left(T_{g}-T_{e m}-f \Omega_{m}\right)
$$

This equation can be written in the ADRC canonical form as below:

$$
\frac{d \Omega_{m}}{d t}=f\left(\Omega_{m}, d, t\right) b_{0} \beta
$$

Where:

f. $\Omega_{\mathrm{m}}$ : Viscous friction torque

$\mathrm{T}_{\mathrm{em}}$ : Electromagnetic torque

$\beta$ : Pitch angle

$\mathrm{T}_{\mathrm{g}}$ : Generator torque

$\Omega_{\mathrm{m}}$ :Mechanical speed

\section{RSC control}

In our study, the decoupling between the active Ps and reactive power Qs is done by the orientation of the quadratic component of the statoric voltage Vsq on the q-axis [1]. In this condition we will have:

$$
\left\{\begin{array}{l}
V_{d s}=\mathrm{O} \\
V_{q s}=V_{s}=\omega_{s} \Phi_{d s}
\end{array}\right.
$$

In the d-q reference frame, the DFIG power can be written as:

$$
\left\{\begin{array}{l}
P_{s}=V_{q s} I_{q s}+V_{d s} I_{d s}=-V_{s} \frac{L_{m}}{L_{s}} I_{q r} \\
Q_{s}=V_{q s} I_{d s}-V_{d s} I_{q s}=V_{s}\left(\frac{\Phi_{s}}{L_{s}}\right)-V_{s}\left(\frac{L_{m}}{L_{s}}\right) I_{d r}
\end{array}\right.
$$

The rotor's voltages are given by:

$$
\left\{\begin{array}{l}
V_{d r}=R_{r} I_{d r}+\sigma L_{r} \frac{d I_{d r}}{d t}-g \omega_{s} \sigma L_{r} I_{q r} \\
V_{q r}=R_{r} I_{q r}+\sigma L_{r} \frac{d I_{q r}}{d t}-g \omega_{s} \sigma L_{r} I_{d r}+g\left(\frac{L_{m} V_{s}}{L_{s}}\right)
\end{array}\right.
$$

We can establish the expression of the currents from the equation (22):

$$
\left\{\begin{array}{l}
\frac{d I_{d r}}{d t}=\frac{V_{d r}}{\sigma L_{r}}-\frac{R_{r} I_{d r}}{\sigma L_{r}}+g \omega_{s} I_{q r} \\
\frac{d I_{q r}}{d t}=\frac{V_{q r}}{\sigma L_{r}}-\frac{R_{r} I_{q r}}{\sigma L_{r}}+g \omega_{s} I_{d r}-g\left(\frac{L_{m} V_{s}}{\sigma L_{r} L_{s}}\right)
\end{array}\right.
$$

With:

Vds, Vqs : Direct and quadratic stator voltages

Vdr, Vqr: Direct and quadratic rotor voltages

Ids, Iqs: Direct and quadratic stator currents

Idr, Iqr: Direct and quadratic rotor currents

$\Phi_{\mathrm{ds}}, \Phi_{\mathrm{qs}}:$ Direct , quadratic stator flux

$\omega s, \omega r$ : Synchronous and Angular speed

The ADRC canonical form of this equation can be written as: 
$\left\{\begin{array}{l}\frac{d I_{d r}}{d t}=f_{d}\left(I_{d r}, d, t\right)+b_{0} u_{d}(t) \\ \frac{d I_{q r}}{d t}=f_{q}\left(I_{q r}, d, t\right)+b_{0} u_{q}(t)\end{array}\right.$

DC bus voltage Control:

According to the power balance of the chain, we have:

$\left\{\begin{array}{l}P_{d c}=u_{d c} i_{d c}=\frac{3}{2} V_{q s} I_{q f} \\ P_{r s c}=u_{d c} i_{r s c}=-P_{r} \\ P_{g s c}=u_{d c} i_{g s c}=-P_{g}\end{array}\right.$

We then obtain:

$$
c u_{d c} \frac{d u_{d c}}{d t}=P_{r s c}-P_{g s c}
$$

With:

$\mathrm{I}_{\mathrm{fq}}:$ The current in the filter in $\mathrm{q}$ axis

$\mathrm{I}_{\mathrm{gsc}}$ : The output current of the rectifier

$\mathrm{I}_{\mathrm{rsc}}$ :The input current of the inverter

If we neglect the power lost in the filter and the electronic switches supposed ideal, we have:

$$
c u_{d c} \frac{d u_{d c}}{d t}=\frac{3}{2} V_{q s} I_{q f}-u_{d c} i_{r s c}
$$

In this equation, Irsc is considered as a load current for the RSC.

To simplify the previous equation in canonical form of the ADRC we put $\omega=\mathrm{Udc}^{2}$ :

$$
\frac{d w}{d t}=f(\omega, d, t)+b_{0} u
$$

Filter current control:

The objective of the control is to ensure a desired Power Factor, $\mathrm{PF}=1$ and to manage the transmission of the rotor power with and without defect, in the d-q axis the filter current equation are given by:

$$
\left\{\begin{array}{l}
L_{f} \frac{d I_{d f}}{d t}+R_{f} I_{d f}+L_{f} \omega_{s} i_{q f}=V_{d s}-V_{d f} \\
L_{f} \frac{d I_{d f}}{d t}+R_{f} I_{q f}+L_{f} \omega_{s} i_{d f}=V_{q s}-V_{q f}
\end{array}\right.
$$

The equation of current in the filter in the canonical form of the ADRC is given by:

$$
\left\{\begin{array}{l}
\frac{d I_{d f}}{d t}=f\left(I_{d f}, d, t\right)+b_{0} u(t) \\
\frac{d I_{q f}}{d t}=f\left(I_{q f}, d, t\right)+b_{0} u(t)
\end{array}\right.
$$

\subsection{Control During Voltage Fault:}

In case of voltage dpis, the high-current saturates the magnetization inductance; the reactive power is absorbed from the grid for the magnetization of the DFIG. As result, the grid voltage will be more and more distributed. 
The purpose of the control is to avoid the trip of the circuit of the DFIG during voltage dips regardless of the type of the fault. It done by limiting the fault current and increasing the DC bus voltage. The flux to the stator is deprived because the stator is directly connected to the network.

However, the quadrature component of the flux is no longer zero and the value of the roper of the park is modified. Under these conditions the statoric and rotoric voltages will be:

$V_{d s}=\frac{R_{s}}{L_{s}} \Phi_{d s}+\frac{d \Phi_{d s}}{d t}-R_{s} \frac{L_{m}}{L_{s}} I_{d r}-\omega_{s} \Phi_{q s}$

$V_{q s}=\frac{R_{s}}{L_{s}} \Phi_{q s}+\frac{d \Phi_{q s}}{d t}-R_{s} \frac{L_{m}}{L_{s}} I_{q r}+\omega_{s} \Phi_{d s}$

$V_{d r}=R_{r} I_{d r}+\sigma L_{r} \frac{d I_{d r}}{d t}-\sigma \omega_{r} L_{r} I_{q r}-\omega_{r} \frac{\mathrm{L}_{m}}{L_{s}} \Phi_{q s}+\frac{\mathrm{L}_{m}}{L_{s}} \frac{d \Phi_{d s}}{d t}$

$V_{q r}=R_{r} I_{q r}+\sigma L_{r} \frac{d I_{q r}}{d t}+\sigma \omega_{r} L_{r} I_{d r}+\omega_{r} \frac{\mathrm{L}_{m}}{L_{s}} \Phi_{d s}+\frac{\mathrm{L}_{m}}{L_{s}} \frac{d \Phi_{q s}}{d t}$

From the equation 33 and 34, we get the following expression for rotor's currents:

$\left\{\begin{array}{l}\frac{d i_{d r}}{d t}=-\frac{R_{r}}{\sigma L_{r}} I_{d r}+\omega_{r} I_{q r}+\omega_{r} \frac{\mathrm{L}_{m}}{\sigma L_{r} L_{s}} \Phi_{q s} \\ -\frac{\mathrm{L}_{m}}{\sigma L_{r} L_{s}} \frac{d \Phi_{d s}}{d t}+\frac{1}{\sigma L_{r}} V_{d r} \\ \frac{d i_{q r}}{d t}=-\frac{R_{r}}{\sigma L_{r}} I_{q r}-\omega_{r} I_{d r}-\omega_{r} \frac{\mathrm{L}_{m}}{\sigma L_{r} L_{s}} \Phi_{d s} \\ -\frac{\mathrm{L}_{m}}{\sigma L_{r} L_{s}} \frac{d \Phi_{q s}}{d t}+\frac{1}{\sigma L_{r}} V_{q r}\end{array}\right.$

This equation can dimension the corrector ADRC. To do this, we can put the equation 35 in the ADRC canonical form:

$\left\{\begin{array}{l}\frac{d i_{d r}}{d t}=f_{d r}\left(i_{d r}, d, t\right)+b_{0} u_{d r}(t) \\ \frac{d i_{q r}}{d t}=f_{q r}\left(i_{q r}, d, t\right)+b_{0} u_{q r}(t)\end{array}\right.$

With:

$\left\{\begin{array}{l}f_{d r}=-\frac{R_{r}}{\sigma L_{r}} I_{d r}+\omega_{r} I_{q r}+\omega_{r} \frac{\mathrm{L}_{m}}{\sigma L_{r} L_{s}} \Phi_{q s} \\ -\frac{\mathrm{L}_{m}}{\sigma L_{r} L_{s}} \frac{d \Phi_{d s}}{d t}+\left(\frac{1}{\sigma L_{r}}-b_{0}\right) V_{d r} \\ f_{q r}=-\frac{R_{r}}{\sigma L_{r}} I_{q r}-\omega_{r} I_{d r}-\omega_{r} \frac{\mathrm{L}_{m}}{\sigma L_{r} L_{s}} \Phi_{d s} \\ -\frac{\mathrm{L}_{m}}{\sigma L_{r} L_{s}} \frac{d \Phi_{q s}}{d t}+\left(\frac{1}{\sigma L_{r}}-b_{0}\right) V_{q r}\end{array}\right.$

And 


$$
\left\{\begin{array}{l}
u_{d r}=V_{d r} \\
u_{q r}=V_{q r} \\
b_{0}=-1 / \sigma L_{r}
\end{array}\right.
$$

\section{Simulation Results}

In order to study the ADRC performance applied to the DFIG during the voltage grid fault, two faults have been simulated successfully:

Fault A: Overvoltage of $15 \%$ for $500 \mathrm{~ms}$.

Fault B: Undervoltage of $80 \%$ for $300 \mathrm{~ms}$.

The both faults $\mathrm{A}$ and $\mathrm{B}$ are shown in figure $\mathrm{N}^{\circ} 4$, as we can see the voltage nominal value increase between 1 second and 1.5 second, and decrease from the instant $t=2.5 \mathrm{~s}$ to $\mathrm{t}=2.8 \mathrm{~s}$.

The simulations of the complete wind conversion chain with the Crowbar resistors and the DC SHOPPER are performed by MATLAB Simulink, the parameters of the studied ADRC and DFIG are given in the appendix.

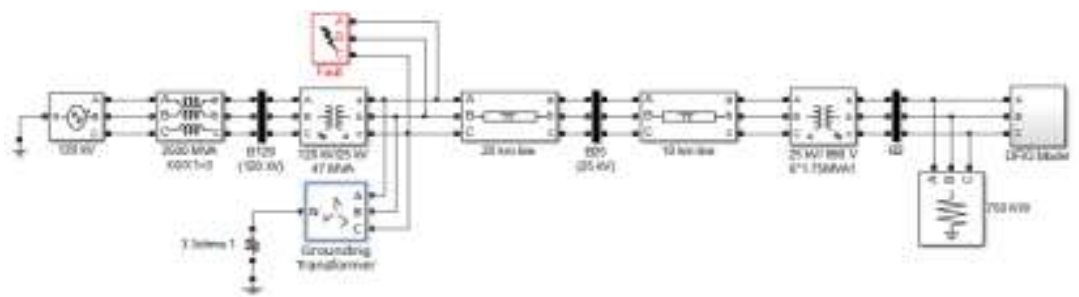

Figure 3. The Simulated System

In this simulation we tried to introduce all the elements constituting an electrical network connected with a turbine and supplying a resistive load, in fact our system consists of a wind turbine of $1.5 \mathrm{MW}$ connected to a $120 \mathrm{Kv}$ electrical network through two power transformers, $25 / 0.690 \mathrm{kv}$ and $25 / 125 \mathrm{kV}$ - 47MVA transformer, the electrical energy generated will carry two lines; $10 \mathrm{Km}$ and $20 \mathrm{Km}$. A resistive load of $750 \mathrm{Kw}$ is connected to the turbine.

As shown in the following figure, under voltage fault is monitored on the $20 \mathrm{Km}$ line, overvoltage fault happened when the load is disconnected.

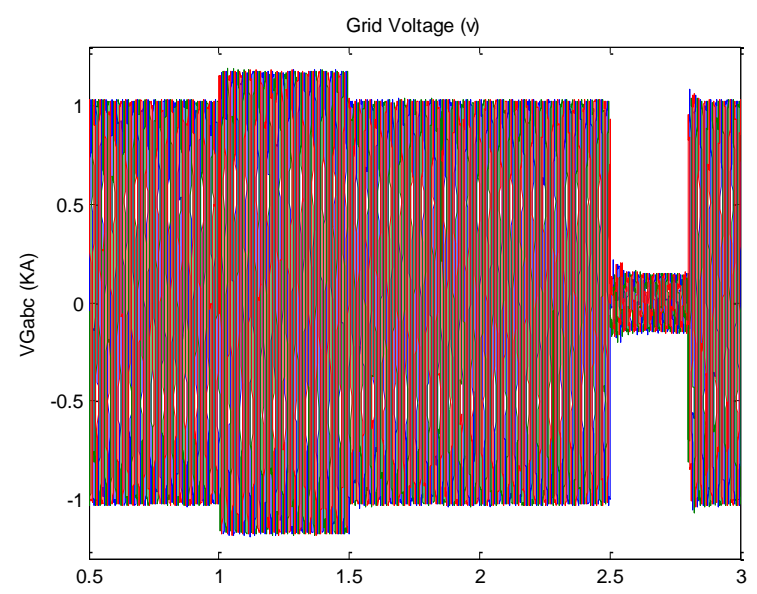

Figure 4. Grid Voltage (pu) $15 \%$ Overvoltage and with $85 \%$ Undervoltage 
To analyze the performance of the ADRC in case of voltage fault (undervoltage and overvoltage) the DFIG is connected to the grid with a perturbed voltage in two times as shows the previous figure:
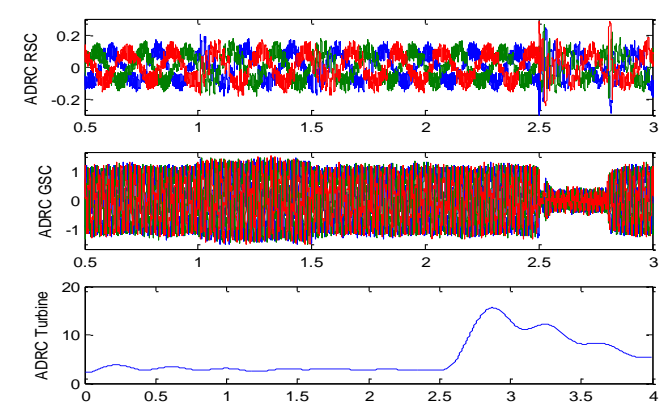

Figure 5. Control Law Generated by the ADRC Bloc for RSC Converter, GSC Converter and Turbine

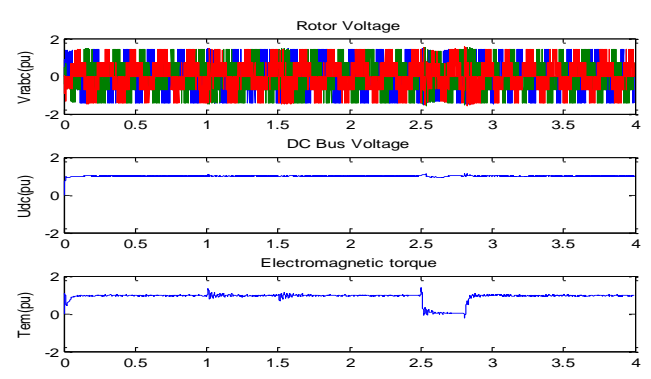

Figure 6. Signals Controlled by ADRC: Rotor Voltage Vrabc, dc Link Voltage Udc and Electromagnetic Torque Tem

\section{Results Interpretation}

From the results we can conclude that the ADRC ensure the high performance for DFIG power control during the voltage grid fault, as we can see in the figure 7, the statoric active power is kept constant during overvoltage grid fault with a little perturbation around $18 \%$ at $\mathrm{t}=1 \mathrm{~s}$ and $13 \%$ at $\mathrm{t}=1.5 \mathrm{~s}$. But the ADRC effect returns the power to its nominal value in $0.3 \mathrm{~s}$ during the under voltage fault. In the other side this power drops nearly to zero in case of undervolatge grid fault.

At the instant $t=2.5 \mathrm{~s}$, the grid absorbs reactive power from DFIG under effect of grid voltage fault and therefore the value of the power factor changes.

The presence of a voltage limiter circuit keeps the rotor side converter connected and ensures the control of the reactive power exchanged between the generator and the grid.

The adopted ADRC control law for turbine increases significantly under voltage fault, hence the rapid increase in the speed of rotation of the generator. As result, the pitch angle $\beta$ changes in order to keep the rotor speed at the rated value.

The signal for GSC control generated by the ADRC bloc is calculated from the network characteristics which gives a form similar to the grid voltage.

From Figure 5, we can conclude that the DC bus voltage Udc keeps his constant value with a little perturbation during voltage fault, but the effect of ARDC maintain this perturbation under acceptable value. 
The evolution of the electromagnetic torque is shown in Figure 5, it drops nearly to zero and keeps constant during grid under voltage, as a result the supplied power dropped significantly.

At the end of this discussion, we note that the parameters of the used ADRC for turbine, GSC and RSC are determined by simulation and are listed in Table 2 of the appendix.

\section{Conclusions}

This paper investigated the performances of ADRC during grid voltage fault such as overvoltage and undervoltage, the ADRC synthesize and control strategy has been clearly developed. In both overvoltage and undervoltage voltage fault, the DFIG still connected to the grid and extchange the power without losing power converter control.

The simulation results show the high performance of ADRC in case of grid voltage fault. In the same way, many articles have evaluated the performance of the ADRC in case of DFIG parameter variation.

In this article, we are not interrested in the frequency behaviour and it will be the topic of our next work research.

\section{Appendix}

Table 1. DFIG Parameters

\begin{tabular}{|l|l|l|l|}
\hline Parameter name & Symbol & Value & Unit \\
\hline Rated power & $\mathrm{P}$ & 1.5 & $\mathrm{MW}$ \\
\hline Statoric voltage & $\mathrm{Vs}$ & $690-50$ & $\mathrm{~V}-\mathrm{Hz}$ \\
\hline Rotoric voltage & $\mathrm{Vr}$ & $389-14$ & $\mathrm{~V}-\mathrm{Hz}$ \\
\hline Statoric resistance & $\mathrm{Rs}$ & 0.012 & $\Omega$ \\
\hline Rotoric resistance & $\mathrm{Rr}$ & 0.021 & $\Omega$ \\
\hline Statoric inductance & $\mathrm{Ls}$ & 0.0137 & $\mathrm{H}$ \\
\hline Rotoric inductance & $\mathrm{Lr}$ & 0.0136 & $\mathrm{H}$ \\
\hline mutual inductance & $\mathrm{Lm}$ & 0.0135 & $\mathrm{H}$ \\
\hline Pole pairs & $\mathrm{P}$ & 2 & \\
\hline The friction Coefficient & $\mathrm{F}$ & 0.024 & N.m.s-1 \\
\hline The moment of inertia & $\mathrm{J}$ & 1000 & kg.m2 \\
\hline
\end{tabular}

Table 2. ADRC Parameters

\begin{tabular}{|l|l|l|l|}
\hline ADRC Parameters & Turbine & RSC & GSC \\
\hline $\mathrm{kp}$ & 7.5 & 130 & 60 \\
\hline $\mathrm{b} 0$ & 0.04 & 253 & 810 \\
\hline$\alpha$ & 0.85 & 0.25 & 0.9 \\
\hline$\beta$ & 0.0001 & 0.001 & 0.001 \\
\hline $\mathrm{Wc}$ & 100 & 150 & 60 \\
\hline W0 & 300 & 400 & 200 \\
\hline
\end{tabular}

\section{References}

[1] A. Boualouch, T. Nasser, A. Essadki, A. Boukhriss and A. Frigui, "A Robust Power Control of a DFIG used in Wind Turbine Conversion System”, International Energy Journal (IEJ), vol. 17, no. 1, (2017), pp. $1-10$.

[2] A. Boukhriss, A. Essadki, T. Nasser and A. Boualouch, "Improved Control for DFIG used in Wind Energy Conversion Systems", International Review of Automatic Control (IREACO), vol. 7, no. 4, (2014), pp. 22-30. 
[3] A. Boukhriss, A. Essadki, T. Nasser and A. Boualouch, "Improved Control for DFIG used in Wind Energy Conversion Systems", International Review of Automatic Control (IREACO), vol. 7, no. 4, (2014), pp. 22-30.

[4] J. Seymour, "The Seven Types of Power Problems, Schneider Electric - Data Center Science Center", White Paper 18 Revision 1 [Online]. http://www.capitolpowergroup.com/sites/ default/files/ APC_Whitepaper_UPS_7-types-of-power-problems.pdf.

[5] A. Farazmand, F. De León, K. Zhang and S. Jazebi, "Analysis, Modeling and Simulation of the PhaseHop Condition in Transformers: The Largest Inrush Currents", IEEE Transaction. Power Del., vol. 29, (2014), pp. 1918-1926.

[6] L. Peng, "Research on Graphical Modeling and Low Voltage Ride Through Control Strategies of Doubly Fed Induction Wind Generator System", PhD. Thesis, Electrical Engineering Department, TSINHGUA University, Beijing, China, (2010).

[7] Q. Zheng, "On Active Disturbance Rejection Control: Stability Analysis and Applications in Disturbance Decoupling Control”, PhD. Thesis, Department of Electrical and Computer Engineering, Cleveland State University, Cleveland, USA. (2009).

[8] W. Zhou, S. Shao and Z. Gao, "A Stability Study of the Active Disturbance Rejection Control Problem by a Singular Perturbation Approach", Applied Mathematical Sciences, vol. 3, no 10, (2009), pp. 491508.

[9] J. Han, "From PID to auto disturbances rejection control", IEEE Transactions on Industrial Electronics, vol. 56 no. 3, (2009), pp. 900-906.

[10] Z. Gao, "Scaling and Bandwidth-Parameterization Based Controller", Proceedings of the 2003 American Control Conference, vol. 6, (2003), pp. 4989-4996.

[11] J. Han, "A class of extended state observers for uncertain systems", Control and Decision, vol. 10, no. 1, (1995), pp. 85-88, (In Chinese).

[12] A. Boukhriss, T. Nasser, A. Essadki and A. Boualouch, "Active Disturbance Rejection Control for DFIG Based Wind Farms under Unbalanced Grid Voltage", International Review on Modeling and Simulations (IREMOS), vol. 7, no. 1, (2014), pp. 95-105.

[13] A. Boualouch, A. Frigui, T. Nasser, A. Essadki and A. Boukhriss, "Control of a Doubly-Fed Induction Generator for Wind Energy Conversion Systems by RST Controller", International Journal of Emerging Technology and Advanced Engineering, vol. 4, no. 8, (2014), pp 93-99.

[14] R. Chakib, A. Essadki and M. Echarkaoui, "Modeling and control of a wind system based on a DFIG by active disturbance rejection control", International Review on Modelling and Simulations (IREMOS), vol. 7, no. 4, (2014), pp. 626-637.

\section{Authors}

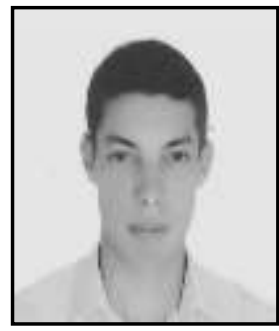

Abdellah Boualouch was born in Sidi-Ifni, Morocco, in 1986. He received a License degree in 2010 and a Master degree in 2012 From ENSET School, Mohammed V University, Rabat. He is currently working toward the Ph.D. degree in the electrical engineering department of ENSET, Mohammed V University, Morocco. His research interests renewable energy, motor drives and power systems. Abdellah.boualouch@um5s.net.ma

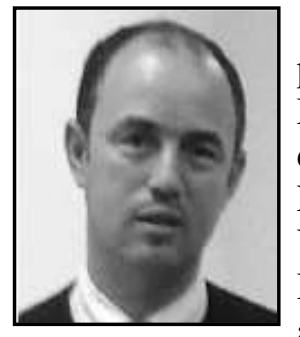

Ahmed Essadki is currently a Professor and university research professor at the electrical engineering department of ENSET, Mohammed V University, Morocco. In 2000, He received his PhD degree from Mohammadia Engineering School (EMI), (Morocco). From1990 to 1993, he pursued his Master program at UQTR University, Quebec Canada, respectively, all in electrical engineering. His current research interests include renewable energy, motor drives and power system. Dr. Essadki is a member of RGE Lab in research group leader. 


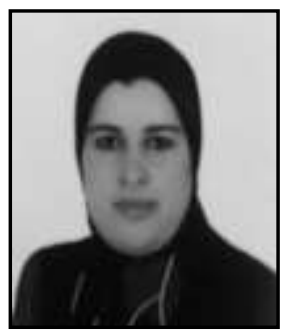

Tamou Nasser is currently an Associate Professor (Professeur Assistant) at the communication networks department of National High School for Computer Science and Systems (ENSIAS), Mohammed V University, Morocco, since 2009. She received her $\mathrm{PhD}$ degree in 2005 and her research MS degree, in 2000, respectively, all in electrical engineering from Mohammadia Engineering School (EMI), Morocco. Her research interests renewable energy, motor drives, power system, and Smart Grid. Dr. Nasser is a member of Al Jazari research group.

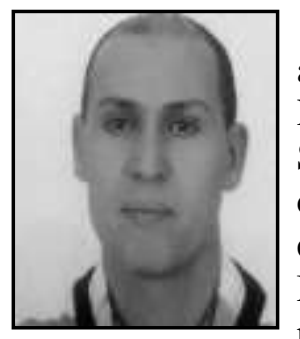

Ali Boukhriss was born in Agadir, Morocco in 1972. He received a License degree from ENSET School, Mohammed V University Rabat in 1993, and a master degree from National School of Applied Sciences of Agadir, Ibn Zohr University Agadir in 2011. He is currently working toward the Ph.D. degree in the electrical engineering department of ENSET, Mohammed V University, Morocco. His research interests renewable energy, motor drives and power systems. 
International Journal of Control and Automation

Vol. 11, No. 9 (2018) 